Article

\title{
A Simple Interpretation of Hubbert's Model of Resource Exploitation
}

Ugo Bardi $^{1,2, *}$ and Alessandro Lavacchi ${ }^{1,2}$

1 Dipartimento di Chimica, Università di Firenze, Via della Lastruccia 3, Sesto Fiorentino FI, Italy

2 ASPO - Association for the Study of Peak Oil and Gas, Italian section, c/o Dipartimento di Chimica, Università di Firenze, 50019 Sesto Fiorentino, Italy;

E-Mail: Alessandro.Lavacchi@unifi.it

* Author to whom correspondence should be addressed; E-Mail: ugo.bardi@unifi.it;

Tel.: +39-055-4573118; Fax: +39-055-4573120

Received: 8 July 2009; in revised form: 4 August 2009 / Accepted: 5 August 2009 /

Published: 13 August 2009

\begin{abstract}
The well known "Hubbert curve" assumes that the production curve of a crude oil in a free market economy is "bell shaped" and symmetric. The model was first applied in the 1950s as a way of forecasting the production of crude oil in the US lower 48 states. Today, variants of the model are often used for describing the worldwide production of crude oil, which is supposed to reach a global production peak ("peak oil”) and to decline afterwards. The model has also been shown to be generally valid for mineral resources other than crude oil and also for slowly renewable biological resources such as whales. Despite its widespread use, Hubbert's modelis sometimes criticized for being arbitrary and its underlying assumptions are rarely examined. In the present work, we use a simple model to generate the bell shaped curve curve using the smallest possible number of assumptions, taking also into account the "Energy Return to Energy Invested" (EROI or EROEI) parameter. We show that this model can reproduce several historical cases, even for resources other than crude oil, and provide a useful tool for understanding the general mechanisms of resource exploitation and the future of energy production in the world's economy.
\end{abstract}

Keywords: Hubbert model; crude oil; depletion; peak oil; energy returned on energy invested; EROEI 


\section{Introduction}

Models are, first of all, methods to help the human mind understand complex realities. No model can exactly predict the future, but what a good model should always do is to give us an idea of what to expect. An area in which models are important is that of resource depletion. The world's economy is based on the availability of a variety of mineral and biological resources; but mineral resources are non-renewable and even biological resources can suffer depletion, as it has happened many times in history.

The prototypical case of resource depletion is that of crude oil in the United States and, in particular, in the lower 48 states. This case was studied first by Marion King Hubbert [1] who proposed already in the 1950s that production would follow a "bell shaped", symmetric curve. Extrapolating the data available at the time, Hubbert was able to successfully predict the peak year for oil production in the US-48: 1970. Today, Hubbert's model is well known and often applied to the whole world's oil production, (e.g., see [2]). The global production peak, expected to occur within the first two decades of the $21^{\text {st }}$ century, is often referred to as "peak oil”. The model can also be applied to resources other than petroleum: there are several resources that have been shown to follow the same bell shaped production curve: coal [3] minerals [4] and biological resources such as whale oil [5] and Caspian caviar [6].

The general applicability and occurrence of bell shaped production curves for the production of all sort of resources has profound implications in the way we should plan for the future. Peak oil marks a critical moment for an economic system which is geared to maintain its growth forever and we may expect it to affect the whole world's economy. But also in many other, more limited cases, peaking is the important moment in the history of the exploitation of a resource.

Although it is difficult to predict the exact date of peaking for a given resource, it can be at least estimated in terms of range. Yet, decision makers seem to be mostly unaware of the concept of "peak production” or consider it arbitrary and unjustified. In most cases, people tend to rely on grossly oversimplified models, such as the ubiquitous "resource to production ratio" which provides a time frame in years which has little relation with reality and which may induce to unwarranted optimism. But, if we need to bring resource depletion to the general attention, we need to explain what generates the bell shaped curve in terms that are generally understandable and acceptable. In other words, we need the kind of model that Seymour Papert [7] has defined as "mind sized" in his book "Mindstorms".

At present, however, the Hubbert model is often misunderstood and criticized for being "arbitrary". It is not so, the model has a logic and has been examined in depth by various methods. Hubbert proposed his model on the basis of purely empirical considerations and perhaps he was influenced by earlier cases of resource depletion, such as anthracite coal in Pennsylvania. The theoretical justifications of the model were only examined in later times. Some interpretations of the model are based on specific characteristics of the exploitation of oil wells (e.g., see [8,9]). However, the model can also be interpreted in terms of more general assumptions; needed in order to explain its general validity for cases other than crude oil. The first theoretical study of Hubbert's curve was based on system dynamics and was presented by Naill [10,11]. A simpler stochastic modelwas developed by Bardi [12] in 2005. Bell shaped production curves can be also obtained starting from assumptions 
based on economics, as done by Reynolds [13] and by Holland [14]. Also the "world models" developed first by Forrester [15] and then by Meadows et al. in the study termed "The Limits to Growth" [16] produce bell shaped curves for the exploitation of natural resources, although normally non symmetric ones.

Here, we will use a simple model in order to examine the general behavior of resource depletion. Our objective is to find a set of basic assumptions that can help decision makers in understanding depletion and its implications. Such a model can be built starting from the well known Lotka-Volterra (LV) model $[17,18]$ also known the "predator-prey" model. The LV model finds few applications in biology since the complexity of ecosystems is not easily captured by the simplified assumptions involved. However, the model is known in economics as applied to "free access" systems [19], in particular to fisheries [20]. This model may not be the simplest possible, but it is the simplest one that includes a feedback loop that links resources and what we call "capital”.

We show that the LV model does generate a Hubbert curve when the "prey" (i.e., the resource) is assumed not to reproduce or to reproduce very slowly. The key factors that generate the curve are the two internal feedbacks that control the model: one is the positive feedback that derives from the reinvestment of the profits generated by the resource, the other the negative feedback that derives from the gradual depletion of the easy, or low cost, resources. What creates the peak is not that the resource has run out; rather, what runs out is the financial capital needed to extract or produce it. Seen in these terms, the Hubbert curve is easy to understand and it appears to be a necessary feature of those economic systems where a mineral (or biological) resource is exploited in a free market system.

We show in this paper that the model can reproduce a number of experimental cases where data are available for both the production of a resource and for the "capital" employed in its production; that is gold extraction, whaling, and oil production in some world regions. Given these results, our model could also be used as a predictive tool; just as other (usually simpler) models based on the Hubbert curve. However, in the present paper we emphasize the use of the model as a tool for understanding the mechanisms of resource exploitation.

The model that we have developed is best used in simple cases where a resource is being extracted (or "produced") in relatively stable market conditions. The model does not take into account factors such as the effects of prices in transferring resources from one sector to another, for instance using coal to extract oil. In other words, the model's application is more to the description of the exploitation of specific resources (e.g., oil in the lower 48 states of the US) than of worldwide resources (e.g., "peak oil”). In the latter case, more complex models are needed for a complete description of the system, such as the ones developed for the "Limits to Growth" studies [16]. These more complex models generate production curves which remain "bell shaped" but that may become asymmetric (see also [12]).

The model that we have developed here allows us also to understand the key role of the "energy yield", also termed "Energy return on energy invested" (EROI or EROEI) [21] along the extraction cycle of a resource. We show that the EROEI declines smoothly with depletion; reaching a nearly constant minimum value which, in some cases, may be smaller than 1 . The peak of production corresponds to the maximum rate of EROEI decline. 


\section{The Model}

We build our model starting from the work of Lotka [17] and Volterra [18] who developed a well known model of "predator-prey" relationships in simple biological systems. In the implementation of the model presented here we assume that there are two main stock variables involved: resources and capital. The amount of available geological (or biological) resource is defined as the "resource stock" $R$. The unit of measurement of $R$ depends on the kind of resource being considered: it may be barrels of oil, bushels of grain or physical units such as energy. $R$ may also be measured in monetary units.

The other main variable of the model is the aggregate amount of economic resources being utilized in the exploitation; that is equipment, land, knowledge, human work, and similar. We call this aggregate amount "capital stock," $C$. Capital will be normally measured in monetary units, but it can also be measured as a parameter proportional to the overall economic effort in a specific productive activity. For instance, we'll show that $C$ can be measured as proportional to the number or the tonnage of the fishing vessels in the case of a fishery.

We define as $R^{\prime}$ and $C^{\prime}$ as the flow (the variation as a function of time) of, respectively, resources and capital. Further parameters of the model are the initial stocks of resource $\left(R_{o}\right)$ and of capital $\left(C_{o}\right)$.

Capital and resources dynamically interact with each other in the same manner as predators and preys interact in the LV model. We assume that the resource (the "prey") can be extracted in proportion to the available capital (the "predator") and, at the same time, in proportion to the amount of the resource stock. Production is therefore in a feedback relationship with two stock variables: resources and capital. This assumption is intuitively justified; the more equipment (e.g., oil rigs) is available, the higher the amount of resource that can be extracted/produced. On the other hand, there must be something to extract and the model assumes that the extraction rate will be proportional to the amount available. Implicitly, this assumption involves that resources are "graded" and that the "easy" (less expensive) resources are extracted (or produced) first.

The other fundamental assumption of the model is that capital is generated in an amount proportional to the amount of extracted resources. In other words, the resource stock is partly transformed into capital stock; let's say that the extracted oil is used to provide the energy necessary to build more oil rigs and other facilities. In more general terms, this transformation is generated via the sale of the resource on the market and the profits are used to create the equipment and facilities to produce more resource. Capital creation, therefore, is in a feedback relationship with the two stock variables: resources and capital.

Finally, we also assume that capital is dissipated over time by depreciation, or obsolescence.

These assumptions can be stated in mathematical form as two coupled differential equations derived from the Lotka-Volterra model. One term of the standard LV model is missing, that of the reproduction of the prey, that here is assumed not to occur or to occur very slowly:

$$
\begin{gathered}
R^{\prime}=-k_{1} C R \\
C^{\prime}=k_{2} C R-k_{3} C
\end{gathered}
$$


There are three constants in the model, which describe how efficiently resources can be extracted or produced $\left(k_{1}\right)$, how efficiently resources are transformed into capital $\left(k_{2}\right)$ and how rapidly capital depreciates $\left(k_{3}\right)$, respectively. The dimensions of the constants depend on the units used for the capital and resource stocks. If both are measured using monetary units, the constants $k_{1}$ and $k_{2}$ have the dimension of a frequency divided by monetary units. The third constant, $k_{3}$ has the dimension of a frequency and is proportional to the speed of obsolescence of capital. Other factors could be taken into account: prices, technological progress, market factors, and others. These effects have been studied, for instance, by Naill [10] and Bardi [12] but will not be examined here as we aim at testing a simple model with the minimum possible number of parameters.

The model can also provide an estimation of the yield of the extraction process as the ratio of the resource being produced at a certain time divided by the amount of capital engaged in production, $\left(R^{\prime} / C\right)$. If both capital and resources are measured in the same units, the yield is thus proportional to $k_{1} R$ and has the dimension of a frequency. If both capital and resources are measured in energy units, this yield parameter is related to the quantity defined as "energy returned on energy invested", EROI or EROEI [21]. The EROEI is a pure number and it results from the integration of the yield over a specific time span, or the total lifetime, of a plant or a system. Yield and EROEI can be used interchangeably when EROEI is obtained by integrating yield over a short time span.

Qualitative solutions of the model were obtained using the Vensim software. For the quantitative fitting of the model to experimental data, we used a combination of the Matlab toolboxes Simulink and Parameter Estimation. Simulink allowed the graphic editing of the Lotka-Volterra equations and its numerical solution by the fourth order Runge-Kutta algorithm. The parameter estimations provided the tool for the non linear least square optimization algorithm to fit the model equations to the extraction and capital data. The fitting procedure was very sensitive on the initial value of the constants to be determined and a good fitting was possible only starting from $k_{1}, k_{2}$ and $k_{3}$ parameters set not too far from the optimized solution.

\section{Results}

Typical qualitative results of the model for the parameters $R, R^{\prime}$ and $C$ are shown in Figure 1. For fixed values of the constants, the model generates a nearly symmetric bell shaped production curve which qualitatively corresponds to the curve described by Hubbert [1]. The capital stock also shows a bell shaped curve, which turns out to be symmetric for values of the depreciation constant, $k_{3}$ higher than a minimum threshold. Note how the peak of the capital stock is shifted forward in time with respect to the production peak. The system continues to accumulate capital for a while after the start of the decline in production. The resource stock curve is, as expected, going down with time but it doesn't necessarily arrive to zero. For sufficiently small values of the capital creation constant, $k_{2}$, and/or sufficiently large values of the obsolescence constant, $k_{3}$, the cycle ends with a large fraction of the resource stock remaining untouched.

The model can also be used to describe the EROEI of the extraction process which, as mentioned earlier on, turns out to be proportional to $k_{l} R$. That is, the EROEI follows the same curve as the resource stock, except that it is scaled for the factor $k_{l}$. The $k_{l}$ constant is therefore a fundamental parameter determining the EROEI of the process. The peak of the production curve is the first 
derivative of the resource stock curve, so that the peak corresponds to the point of maximum change of the EROEI. This result is independent of the absolute value of the EROEI that may reach and maintain values smaller than one during the late phases of the extraction cycle.

Figure 1. Qualitative solutions of the model described in the present paper. The three parameters shown are 1) the production rate (upper curve), 2) the amount of resource available (middle curve) and 3) the accumulated capital (lower curve).

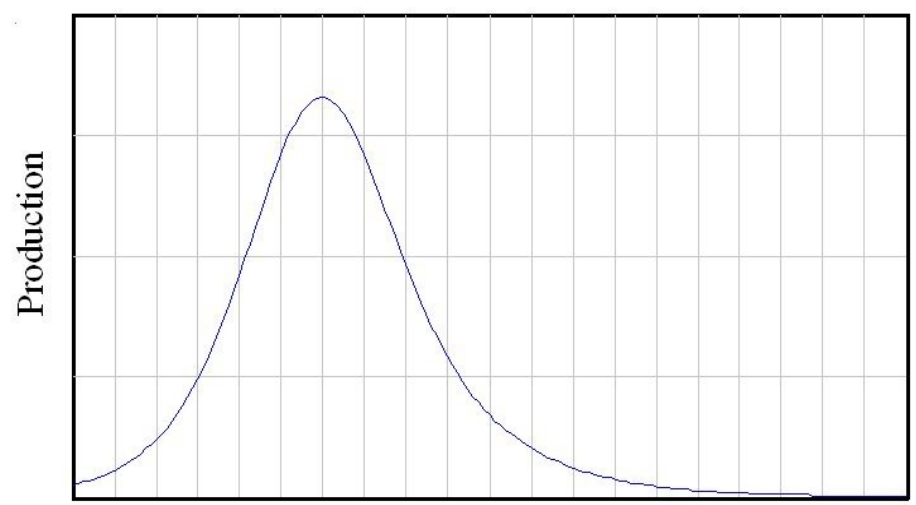

Time
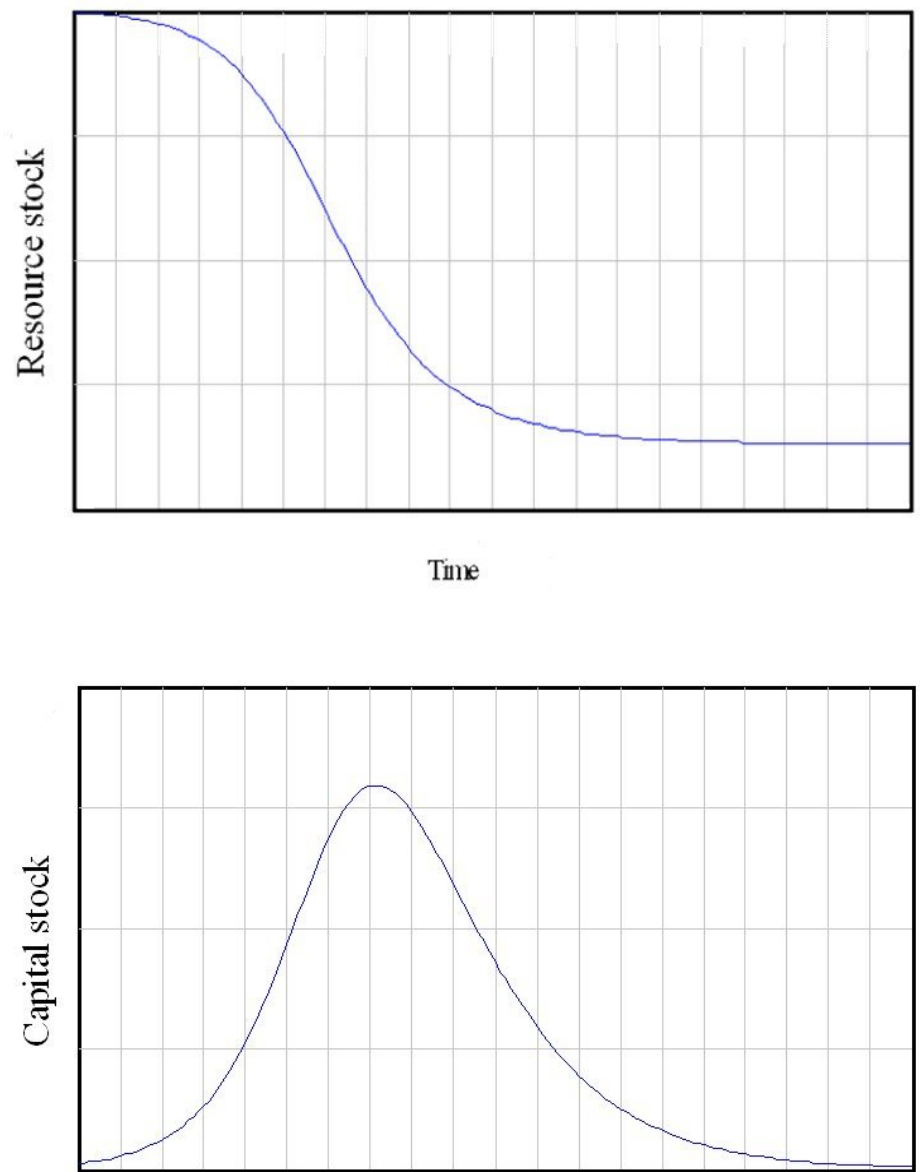

Time

The production curve generated by the model is compatible with the known historical curves for resource production. As an example, in Figure 2 we show the fitting of the model to oil production in 
the US lower 48 states, the system that Hubbert studied first. The fit is good and this result shows that the modified LV model proposed here is compatible with the Hubbert curve as it is normally proposed and understood.

Figure 2. Oil production in the US lower 48 states, fitted using the model developed in the present paper (data courtesy of Mr. Colin Campbell).

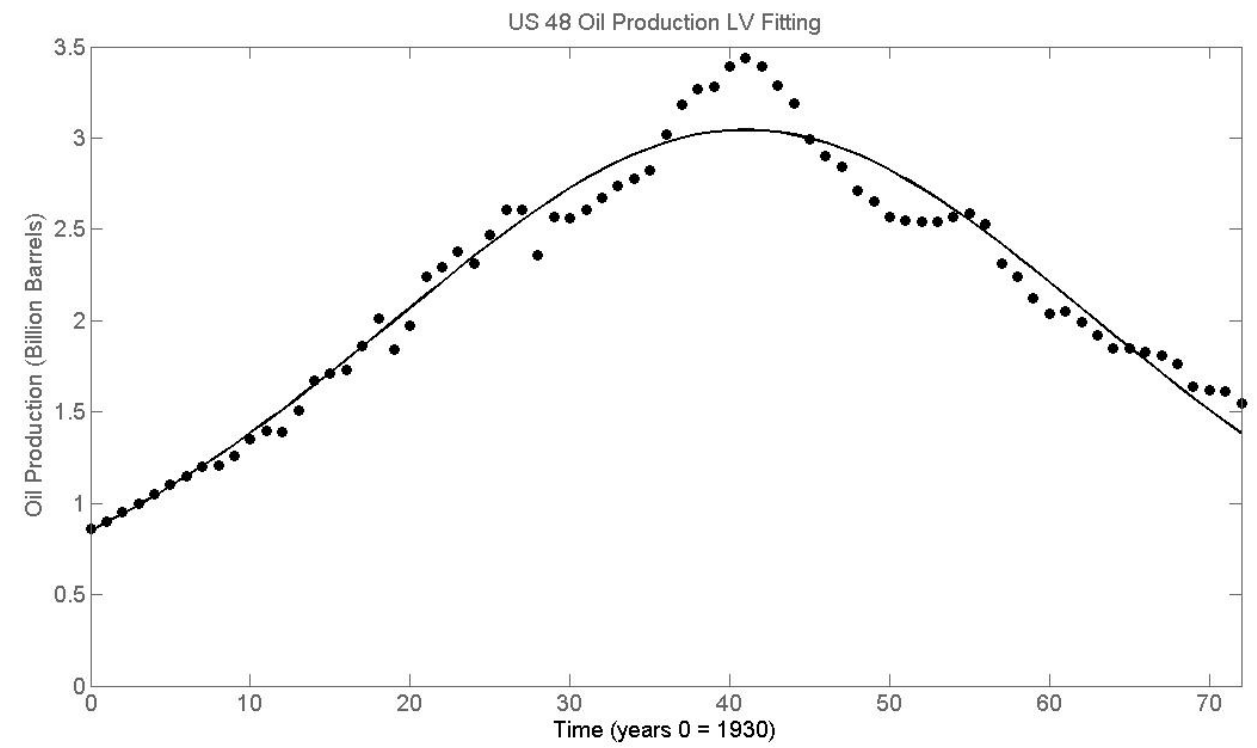

However, the ability of fitting a single bell-shaped curve is not, in itself, a confirmation of the validity of our model, since many different models can do that. Instead, a critical test for the model is the ability of fitting to the experimental data not just one of its parameters, but both the main parameters at the same time: production and capital. As we will show in the following, the model was found to be able to fit only cases in which the whole capital stock curve was suitably shifted to later times in comparison to the resource production curve, as expected for a predator/prey relationship. In other words, our model is not a "fit-all" model.

It turned out that the number of cases in which fitting the experimental data is possible was very limited. Mainly, this difficulty is related to the problem in obtaining data on the "capital" parameter. Production data are normally published in industry and financial reports and are easily available; but it is rare that these reports also contain an estimate of the economic effort placed in a specific area for the extraction or production of a specific resource. In the following, we'll show some cases in which the capital parameter could be reasonably estimated as proportional to other, available, parameters and we'll show how a good fitting to the historical data can be obtained.

\subsection{Gold Mining in California and in South Africa}

The first gold rush in modern history is the one that took place in Californa, starting around 1848. Gold production rose rapidly, as did the number of people engaged in gold mining. However, the hot phase of the cycle lasted just about ten years. Afterwards, gold continued to be produced by industrial processes in California mines, but no longer by enterprising miners armed with shovels and iron pans. 
Data for the amount of gold mined-expressed in term of its value in dollars - and for the number of miners engaged can be found in the book by Rodman W. Paul, "California Gold” [9]. The available data cannot be defined as complete, nor fully reliable. In particular, expressing gold production in monetary units doesn't take into account inflation. However, the period examined is brief and so inflation may have played a minor role.

For the analysis of the California gold rush, the production parameter is, obviously, gold production. For the "capital” parameter, in this relatively low tech situation, may be seen as approximately proportional to the number of miners involved in the extraction, at least during the initial phases of extraction. The results of the fitting are shown in Figure 3.

Figure 3. Gold production and number of miners during the "Gold Rush" in California fitted using the LV model developed here. The data are from [22].

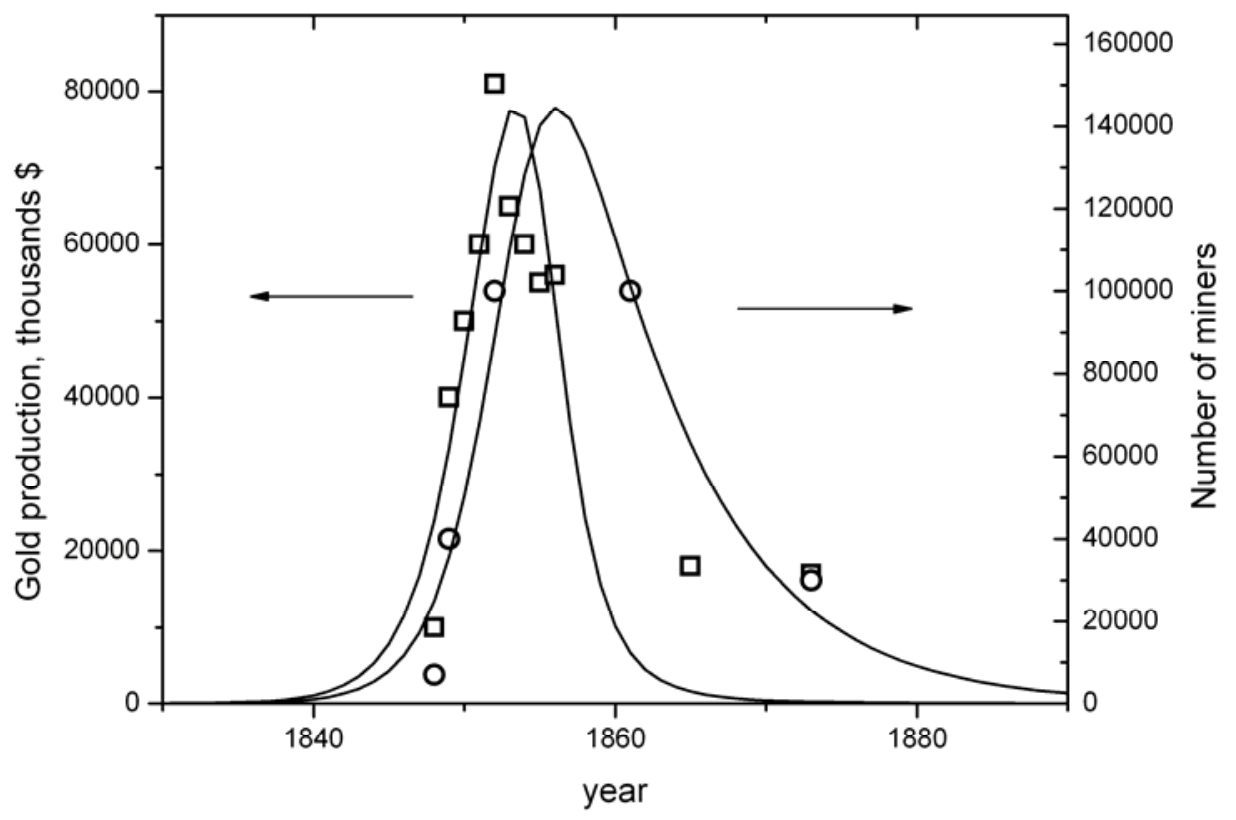

The calculated curve of gold production is bell shaped and it fits well the first years of the gold rush. Later on, the historical gold production does not go to zero as the model would calculate. As discussed before, there was more than a single cycle of exploitation after the first, heroic phase of mining by the "forty-niners". However, for the purposes of the present work, the fitting obtained does prove that the modified Lotka-Volterra approach is at least qualitatively consistent with the historical data.

More recent data on gold mining are relative to South Africa [23]. In this case, the relation of gold mined to the number of gold miners is similar to the one for California, that is, the number of miners peaks much later, in 1990, than the amount of gold mined (in 1970). However, in this case, we have data on the total mass of ore mined. Also this parameter may be considered proportional to the overall effort of the mining industry to mine gold and, therefore, to the aggregate stock that we called "capital". The results of the fitting are shown in Figure 4. Also here the fitting is only approximate and it was not possible to use the model to account for the early stages of the exploitation cycle. Evidently, also here there was more than one cycle of mining. However, the data do show a qualitative agreement with the model. 
Figure 4. LV model fitting of gold production in South Africa. In this case, the resource is the gold itself, while the amount of ore mined can be assumed to be proportional to the effort (i.e., the capital) placed by the gold industry in extraction. Data are from [23].
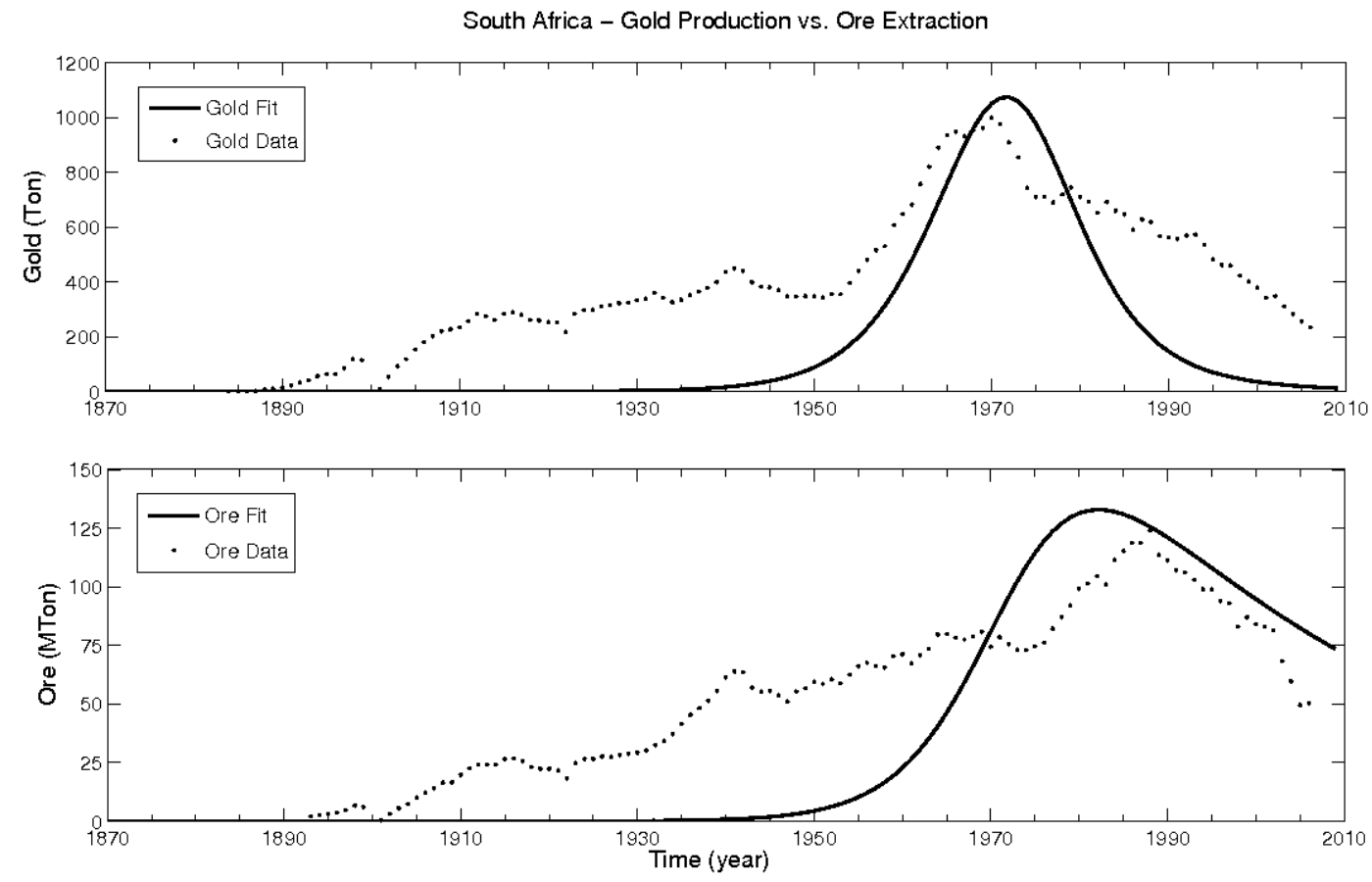

\subsection{Whaling in the $19^{\text {th }}$ Century}

Whaling in the $19^{\text {th }}$ century is a nearly ideal case of an open access biological resource exploited under free market conditions at a rate much faster than it is replenished. The $19^{\text {th }}$ century whaling has been examined in a number of studies [24]. The evident relation of the system with the Hubbert model was recognized first by Coleman [25] and later by Bardi [5]. However, to our knowledge, the whale oil production curve has never been quantitatively analyzed using a model based on the Lotka-Volterra equations.

The experimental data examined here are those reported by Starbuck's in his 1878 book for whale oil production of the American whale fisheries from 1807 to 1876 [26]. Further data from other sources can be found in the literature [24], but Starbuck's data present a consistent picture which is sufficient for the purposes of the present analysis.

In the $19^{\text {th }}$ century, at least five species of whale were hunted by American whalers [24]. The data examined here are relative to the two main species hunted: the "sperm whale" and the "right whale." Production is expressed in terms of the amount of whale oil; the main aim of whale hunting at the time. Whales were also hunted for "whale bone” or baleen, which was used as a stiffening material for clothing. The production trend for whale bone is very similar to that of whale oil and it will not be examined here.

In Figure 3, Starbuck's data [26] are fitted with the Lotka-Volterra model that we described in the previous section. Whale oil production is defined as the sum of the production of right and sperm whale oil. As "capital”, we took the total tonnage of the whaling fleet; very similar results are found if we use instead the number of whaling vessels. 
Figure 5. Data for whaling in $19^{\text {th }}$ century fitted by the model developed in the present study. In this case, the resource is whale oil, while a measure of the capital invested in production can be taken as proportional to the total tonnage of the whaling vessels. Data are from [26].
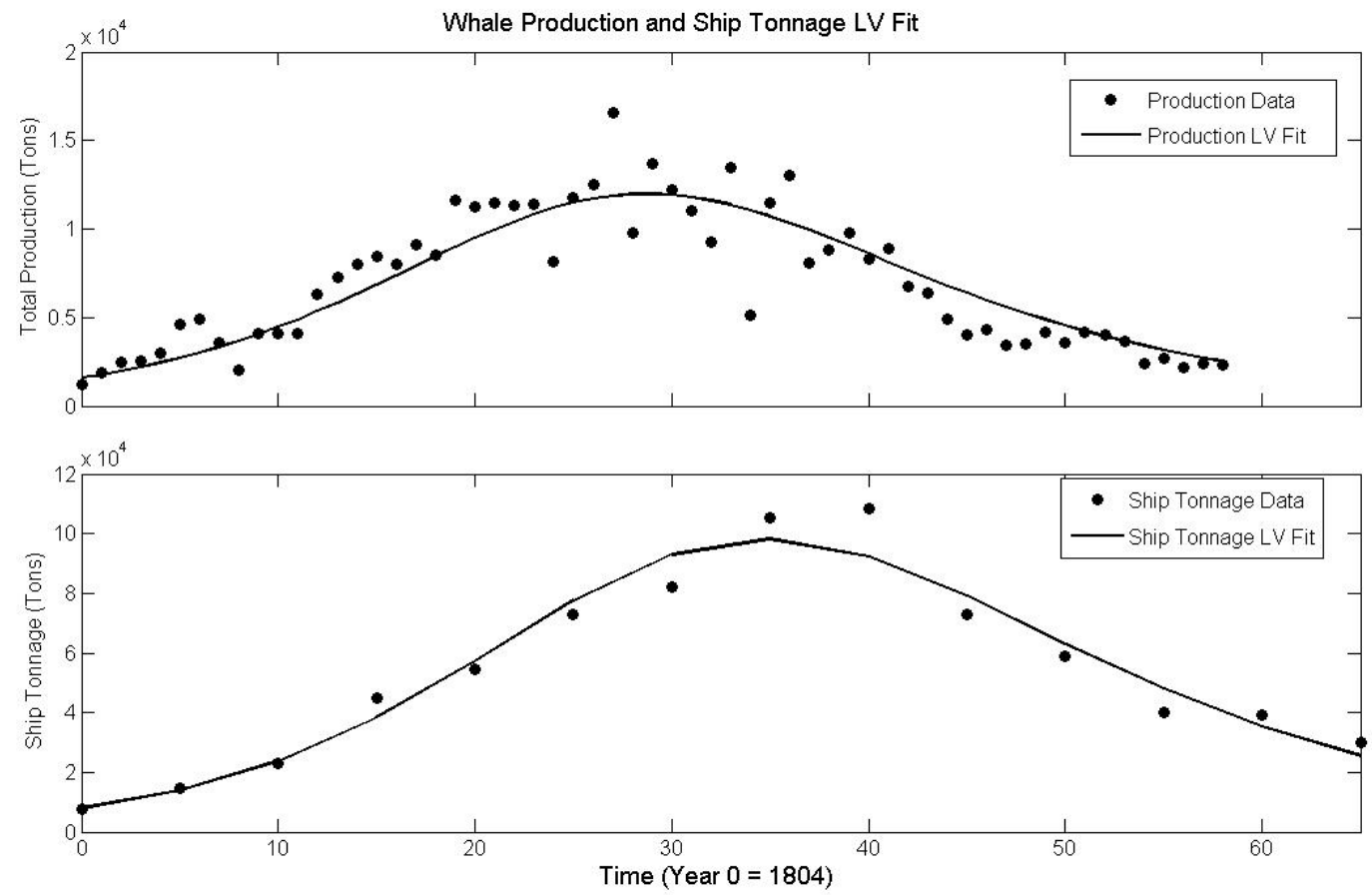

As we see, the fit is good if we take into account the dispersion in the historical data. In order to fit the experimental data, it was not necessary to assume that whales reproduce. In other words, the reproduction rate was negligible in comparison to the capture rate and whales behaved as non renewable resources. This result shows that the tonnage (or number) of whaling vessels is a good indication of the aggregate "capital” expended by the whaling industry in the activity of searching and capturing whales.

\subsection{Crude Oil Extraction in the US Lower 48 States and in Norway}

The case of oil production in the US lower 48 states is the one that Hubbert himself used as a test for his theory. We already showed in Figure 2 how the model can produce a good fit to the historical production curve. However, it was not possible to find data for the capital involved in the extraction of oil in the lower 48 states only, nor for other historical cases of oil extraction.

A different approach turned out to be successful. The key point in interpreting oil production data lies in considering the relatively long interval of time from the discovery of a resource and its exploitation. This delay has been observed in nearly all productive regions of the world. In the case of the 48 US states, the production curve mirrors nearly exactly the discovery curve, except that it is delayed by about 35 years.

Now, it is obvious that oil cannot be extracted (or "produced") if it has not been discovered first and the available data indicate that discovery is a more expensive and difficult process than development and extraction. In other words, once that oil has been discovered, development and extraction 
is a nearly automatic process and the resulting production curve simply mirrors the smoothed discovery curve.

On the basis of these considerations, we examined the discovery data for the US lower 48 states as the "resource" parameter. For the "capital" parameter, we considered the number of "wildcats" (exploratory drillings) as an indication of the effort invested by the oil industry in the discovery process. In other words, discoveries were considered as the "prey", while exploratory rigs as the "predator". Note that just discovering a well would appear not to produce capital, and that would seem to be in contradiction with the assumptions of the model. However, in a financial system such as the one in which the oil industry operates, a discovered well does produce capital in the sense that it attracts it from investors.

Figure 6. Fitting of the data for oil discovery in the US 48 lower states and of the number of wildcats. In this case, the number of wildcats is proportional to the capital used by the oil industry in the effort of discovering the resource (oil wells). Data by courtesy of Messrs. Colin Campbell and Jean Laherrere.

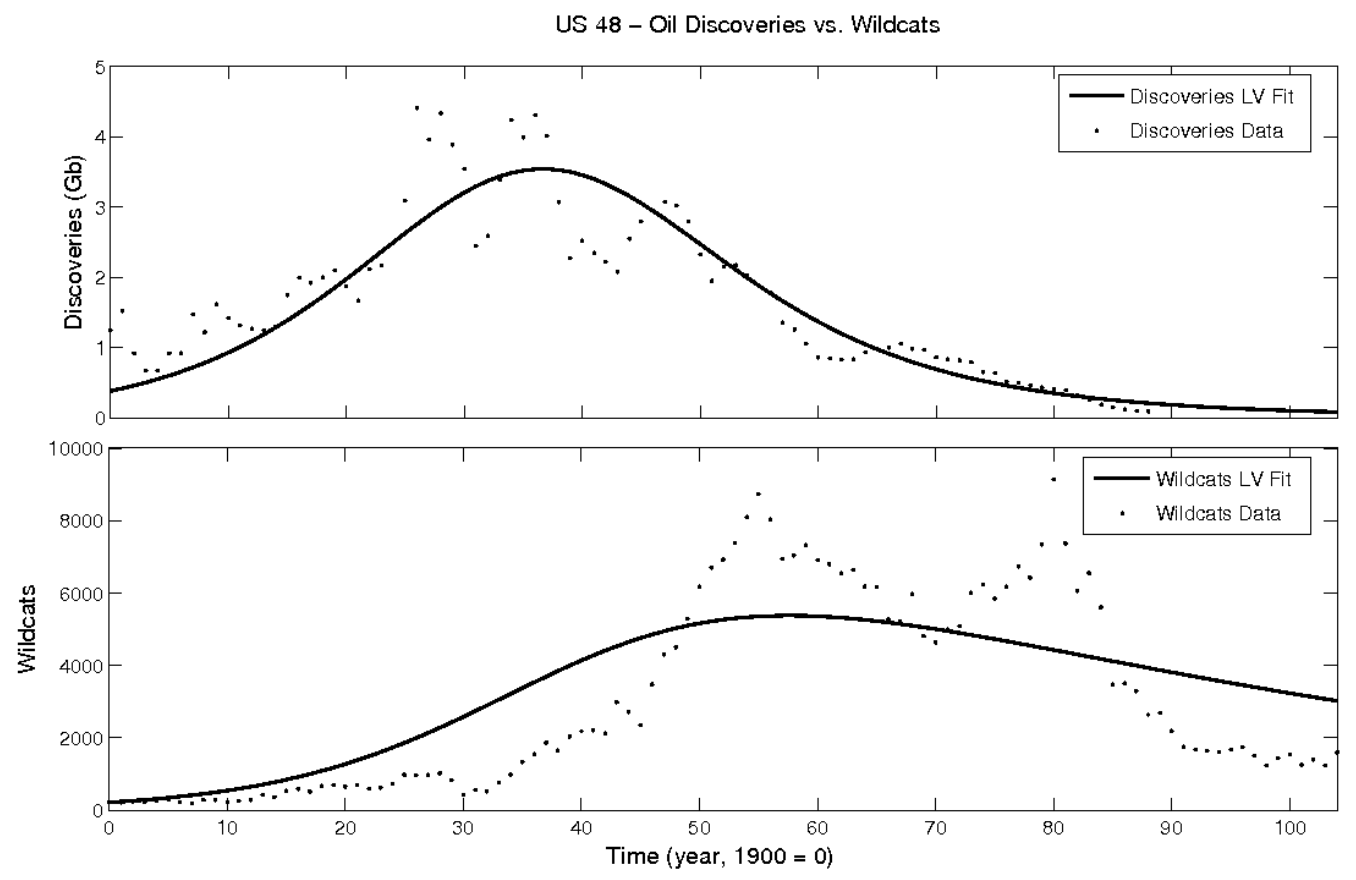

Data for oil discovery in the 48 US states were obtained from the ASPO database (courtesy of Mr. Colin Campbell) and the data for the wildcats were kindly provided by Mr. Jean Laherrere. The results indicate that this interpretation is substantially correct, as shown in Figure 4. The agreement of the theory with the data is not perfect, but the trend is unmistakable: wildcats show a maximum at a later time than the discovery peak. These results show that the modified LV model is applicable to oil production.

Note how the oscillations of the number of wildcats are related on how market conditions, i.e. prices, affect the exploration effort. In particular, the US 1970 peak generated the spike in oil prices that is known today as "the great oil crisis" of the 1970s. This spike in oil prices generated an increase in the number of wildcats drilled, but didn't lead to a corresponding spike in the number of discoveries and the number of wildcats soon returned to the expected trend according to the model. 
A second case examined with the same parameters was that of oil discovery and wildcats for Norway. Here, the agreement with the LV model is clear, better than for the case of the 48 US states.

Figure 7. Fitting of the data for oil discovery in Norway and of the number of wildcats. In this case, the number of wildcats is proportional to the capital used by the oil industry in the effort of discovering the resource, oil wells. Data by courtesy of Messrs. Colin Campbell and Jean Laherrere.

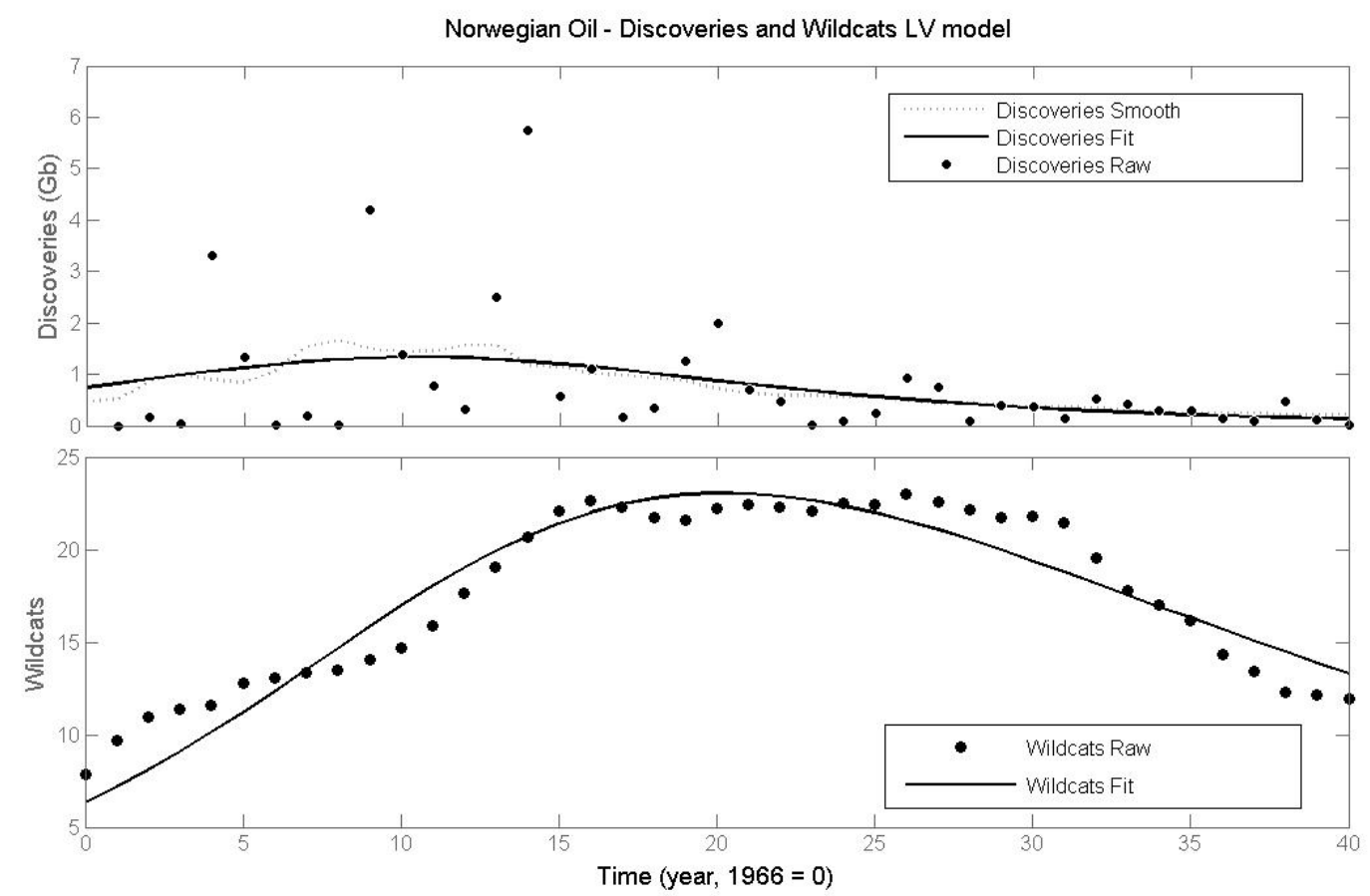

\section{Discussion}

It is easy to find bell shaped production curves in history. Such curves are observed for fossil fuels, typically for petroleum, but also for coal [3] and many other minerals [4]. Bell shaped curves are also observed for biological resources [5,6]. There are exceptions, of course, but a single peak seems to be the rule whenever production occurs in a free market and in reasonably stable social and political conditions.

There are several models that can produce bell shaped curves that fit the historical data. At the simplest level, the curve can be considered as the basic assumption of the model and it can be reproduced using a simple logistic curve. The curve can also be interpreted as the result of specific characteristics of oil wells; that is as due to the gradual loss of pressure of the reservoir (e.g., see $[2,8,9])$. However, this interpretation doesn't explain why other resources, from coal to whales, follow the same kind of curve. The question of why oil production goes up in the initial stages has been approached in various ways. Naill $[10,11]$ simply assumes that demand grows exponentially because of external (or "exogenous”) market factors. Reynolds [13] considers that the growth is due to the gradual improvement of the ability of operators to find and exploit the resource. Holland [14] examines both assumptions, exogenous demand growth and technological improvement. Modelling decline is easier and all models assume that it is due to an increasing cost of producing the resource as 
the stock becomes depleted. Another system dynamics approaches to the model was reported by Davidsen et al. [27]. About the effect of EROEI on production curves, it is worth citing the paper by Bassi et al. [28] which examines the whole world's energy production. Our approach is also related to the "cheese slicer" model described in the recent paper by Hall et al. [29] which can also be seen as a "mind sized" model.

These models are all valid, within a certain range of data and assumptions. In the present work, we have approached the problem looking for a model that generates the bell shaped curve which would be, at the same time, (1) not based on arbitrary assumptions, (2) using the smallest possible number of parameters and (3) "mind sized" that is that it can be easily grasped by the human mind. The Lotka-Volterra model, in the version developed here, is a "mind sized" model which provides a simple theoretical framework that generates the bell shaped curve. The number of historical cases where the model can be tested in full is still limited, but it is significant.

The origin of the bell shaped curve, in this vision, is completely endogenous to the productive system. We have assumed that a constant fraction of the revenues for production are invested in the creation of capital that generates more production. It is this positive feedback that generates the growing side of the curve. The negative feedback, the other side of the production system, derives from depletion and obsolescence. It is implicit in the model that the cost of extraction increases as an inverse fraction of the remaining amount of resource to be transformed. Eventually, this negative feedback takes over, causing a slowdown of the growth which generates a peak and the successive decline. It is this set of assumptions that generates a curve that reproduces the historical data, as we saw in the case studies of the previous chapter. It is especially important that the model generates two curves that can provide a critical test of its validity by comparing the model results with the real world data.

Our model is limited in the sense that it does not into account the "rest of the world". In particular, it doesn't take into account prices and technological advances. Of course, the model could be modified to take into account these parameters. If we consider prices, in particular, the model would become very similar to the "cheese slicer" model described by Hall et al. [29]. This model (incidentally, also a "mind sized" one) assumes that the economy can be likened to a giant dairy factory. It contains a feedback cycle that links the stock of the resource being produced to the need of providing resources (“capital”) to production. Production generates these capital resources which, however will also have to be used to create "staples" and "discretionary" goods. With declining EROEI, the system needs more resources (i.e., energy) to keep producing at the same rate. In a market system, this need will be manifested by higher prices of the resource. These higher prices will lead consumers to reduce discretionary expenses to maintain the supply of the resource. Eventually, however, prices can rise at levels so high that consumers will refuse to further reduce their discretionary slice. At this point, production will fall (and prices, too). In any case, the discretionary slice cannot be thinner than zero thickness, so that production is destined to fall one day or another.

In more general terms, in the real world, the parameter "capital" is not totally endogenous in the model, but it comes from other sectors of the economy. This factor can postpone the peak and increase the amount of resource extracted. It can cause the curve to become asymmetric [12], but will not change the basic features of the model and of the extraction process. 
A similar effect is observed if the technological improvement is included as affecting the efficiency of production. A more efficient use of capital will be equivalent to having more capital and we go back to the previous case. By adding more parameters and elements, the simple LV model developed here can — eventually — morph into the "world models" developed first by Forrester [15] and the by the MIT team [16] that created the "Limits to Growth" study. The curves for industrial and agricultural production of "The Limits to Growth" are bell shaped, but skewed forward as an indication that the symmetric curve of the Hubbert model is an approximation. Nevertheless, we have shown here that, in some limited conditions, even this approximate model can provide a good fitting to historical data and therefore can be a good model to understand how the real world works.

Our model can also be used to evaluate a crucial parameter in the extraction of oil and of other energy producing resources: the energy returned for energy invested, EROEI [21]. We found that the yield (instantaneous EROEI) goes down following the same curve as that of the resources. The production peak corresponds to the first derivative of the resource curve; that is to the point of maximum variation of the EROEI curve. Considering the absolute values of the EROEI curve, there is no direct relationship with the peak position. The decline of production normally starts occurring for values of the EROEI larger than one. However, in the final phases of the extraction cycle, the EROEI may reach values smaller than one and maintain this value for a production larger than zero. In economic terms, it would seem not to make sense to produce energy at EROEI $<1$. However, this is perfectly possible in the real world. One reason is that the monetary profit from extraction may be influenced by non market factors, such as subsidies. It may also be possible to keep extracting a resource because of its specific characteristics - for instance, if one needs liquid fuels, it could make sense to use energy from natural gas to extract crude oil, even at EROEI $<1$. The model, however, does indicate that it is a general feature of these systems that lower EROEI is associated with gradually lower rates of extraction. These result are in qualitative agreement with the known data on the EROEI of oil extraction (e.g., see [28]) which indicate a gradual decline from values of about 100 at the beginning of the extraction cycle to values of about 10 at present.

\section{Conclusions}

We have shown here how a simple model based on the classic "Lotka-Volterra" model can be used to fit several historical cases in which the production of a non-renewable, or slowly renewable, resource has shown a bell shaped behavior. The purpose of this model is to provide a useful mental tool ("mind sized") that can help us to understand the behavior of the economy when it comes to exploit non renewable or slowly renewable resources. Our model can be used, in principle, as a predictive tool but it does not pretend to be able to make predictions better than those made by other methods. In general, the model tells us that, for mineral resources, depletion is not a question of physics or economics alone. Neither purely physical factors, that is depletion, nor purely economic ones, can explain the peak. 


\section{Acknowledgements}

The authors are grateful to Messrs. Colin Campbell and Jean Laherrere for providing the data on oil discovery and number of wildcats in the US and in Norway. We thank also Mr. Juergen Muller for the data on gold production in South Africa.

\section{References}

1. Hubbert, M.K. Energy Resources. A Report to the Committee on Natural Resources; National Academy of Sciences, National Research Council: Washington, DC, USA, 1962; p. 54.

2. Campbell, C.J.; Laherrère, J.H. The End of Cheap Oil. Sci. Amer. 1998, March, 78-83.

3. Bardi, U. Peak oil's ancestor: the peak of British coal production in the 1920s. ASPO: Uppsala, Sweden, 2007.

4. Bardi, U.; Pagani, M. Peak Minerals. The Oil Drum: Europe, 2008. Available online: http://www.theoildrum.com/node/3086 (accessed August 12, 2009).

5. Bardi, U. Energy Prices and Resource Depletion: Lessons from the Case of Whaling in the Nineteenth Century. Energy Sources Part B 2007, 2, 297-304.

6. Bardi, U.; Yaxley, L. How General is the Hubbert Curve? The Case of Fisheries. In Proceedings of the 4th International ASPO Conference, Lisbon, Portugal, 2005. Avalable online: http://europe.theoildrum.com/files/bardiyaxleyaspo2005.pdf (accessed August 12, 2009).

7. Papert, S. Mindstorms; Basic Books: New York, NY, USA, 1980.

8. Bentley, R.W. Global oil and gas depletion. Energ. Policy 2002, 30, 189-205.

9. Stark, D. An Oil Production Model from Roger Bentley. The Oil Drum: Europe, 2008. Available online: http://www.theoildrum.com/node/4382 (accessed August 12, 2009).

10. Naill, R.F. Managing the Discovery Life Cycle of a Finite Resource: A Case Study of U.S. Natural Gas. Master Thesis, Massachusetts Institute of Technology: Cambridge, MA, USA, 1972.

11. The Discovery Life Cycle of a Finite Resource. In Towards Global Equilibrium: Collected Papers; Meadows, D.L., Meadows, D.H., Eds.; Business \& Economics: Geneva, Switzerland, 1973.

12. Bardi, U. The Mineral Economy: A Model for the Shape of Oil Production Curves. Energ. Policy 2005, 33, 53-61.

13. Reynolds, D.B. The Mineral Economy: How Prices and Costs Can Falsely Signal Decreasing Scarcity. Ecol. Econ. 1999, 31, 155-166.

14. Holland, S.P. Modeling peak oil. The Energy Journal 2008, 29, 61-80.

15. Forrester, J.W. World Dynamics. Wright-Allen: Cambridge, MA, USA, 1971.

16. Meadows, D.H.; Meadows, D.L.; Randers, J.; Behrens, W.W., III. The Limits to Growth; Potomac Associates: New York, NY, USA, 1972.

17. Lotka, A.J. Elements of physical biology; Williams \& Wilkins Co: Baltimore, MD, USA, 1925.

18. Volterra, V. Variazioni e fluttuazioni del numero d'individui in specie animali conviventi. Mem. R. Accad. Naz. dei Lincei. 1926, Ser. VI, 2, 31-113.

19. Clay, C.; Wright, K. Order without law? Explor. Econ. Hist. 2003, 42, 155-183.

20. Smith, V.L. Economics of Production from Natural Resources. Am. Econ. Rev. 1968, 58, 409-431. 
21. Hall, C.A.S.; Balogh, S.; Murphy, D.J.R. What is the Minimum EROI That a Sustainable Society Must Have? Energies 2009, 2, 25-47.

22. Paul, R.W. California Gold; University of Nebraska Press: Lincoln, NE, USA, 1947.

23. Chamber of Mines of South Africa. Available online: http://www.bullion.org.za/Econ\&Stats/ HistoricalGoldData2.htm (accessed August 11, 2009).

24. Davis, L.E.; Gallman, R.E.; Gleiter. K. In Pursuit of the Leviathan; University Of Chicago Press: Chicago, IL, USA, 1997.

25. Coleman, C. The American Whale Oil Industry: A Look back to the Future of the American Petroleum Industry? Nat. Resour. Res. 1995, 4, 273-278.

26. Starbuck, A. History of the American Whale Fishery; Castle: Secaucus, NJ, USA, 1989.

27. Davidsen, U.; Sterman, J.D.; Richardson, G.P. +A petroleum life cycle model for the United States with endogenous technology, exploration, recovery, and demand. Syst. Dynam. Rev. 1990, 6, 66-93.

28. Bassi, A.M.; Powers, R.; Schoenberg, W. An Integrated Approach to Energy Prospects for North America and the Rest of the World. Energy Econ. 2009, doi:10.1016/j.eneco.2009.04.005.

29. Hall, C.A.S.; Powers, R.; Schoenberg, W. Peak Oil, EROI, Investments and the Economy in an Uncertain Future. In Biofuels, Solar and Wind as Renewable Energy Systems: Benefits and Risks, Pimentel, D., Ed.; Springer: New York, NY, USA, 2008.

(C) 2009 by the authors; licensee Molecular Diversity Preservation International, Basel, Switzerland. This article is an open-access article distributed under the terms and conditions of the Creative Commons Attribution license (http://creativecommons.org/licenses/by/3.0/). 